\title{
Results of radiosurgery for brain stem arteriovenous malformations
}

Hiroki Kurita, Shunsuke Kawamoto, Tomio Sasaki, Masahiro Shin, Masao Tago, Atsuro Terahara, Keisuke Ueki, Takaaki Kirino

\begin{abstract}
Objective-To assess the treatment results of radiosurgery for brain stem arteriovenous malformations (AVMs) and to seek optimal dose and treatment volume prescription for these lesions.

Methods-The clinical and radiological data of 30 consecutive patients with brain stem AVM treated with gamma knife radiosurgery were retrospectively reviewed with a mean follow up period of 52.2 months. There were 26 patients with previous haemorrhages and 21 with neurological deficit. Seventeen AVMs were located in the midbrain, 11 in the pons, and two in the medulla oblongata. All of the lesions were small with the intra-axial component occupying less than one third of the area of brain stem parenchyma on axial section of multiplaner MRI or CT. The mean diameter of the nidus was $1.26 \mathrm{~cm}$, and the nidus volume within the brain stem parenchyma ranged from 0.1 to $2.0 \mathrm{~cm}^{3}$. The mean radiation dose to the AVM margin was 18.4 Gy.

Results-The actuarial 3 year obliteration rate was $52.2 \% ; 69.4 \%$ in cases treated with standard doses (minimum target dose, 18-20Gy), and $14.3 \%$ in cases treated with low doses $(<18 \mathrm{~Gy})(\mathrm{p}<0.05)$. Two patients sustained symptomatic radiation injury, but there was no permanent neurological deficit caused by radiosurgery. Five patients had haemorrhage from the AVM after irradiation, including four fatal cases, resulting in a $4.0 \%$ annual rate of post-treatment bleeding.

Conclusions-Radiosurgery is a viable treatment modality for patients with small deep parenchymal brain stem AVMs. A standard radiosurgical dose is safe and effective when directed to a small treatment volume. However, latent interval haemorrhage remains a significant problem until the nidus is obliterated completely.

(F Neurol Neurosurg Psychiatry 2000;68:563-570)
\end{abstract}

Keywords: gamma knife, radiosurgery, arteriovenous malformation, brain stem

During the past two decades, stereotactic radiosurgery has been widely used for the treatment of cerebral arteriovenous malformations (AVMs). Several authors described successful radiosurgical results of AVMs located in the critical areas of the brain, ${ }^{1-5}$ but, as for the long term results in the brain stem AVMs, little information is available on this relatively new treatment modality. ${ }^{67}$ Although radiosurgery is apparently considered as a valid treatment, ${ }^{89}$ it is also known to cause serious neurological deterioration when used for brain stem lesions, ${ }^{10-14}$ and at present, no widely accepted standard protocols of radiosurgery in this region have been established. To add to such still limited knowledge, we retrospectively reviewed 30 consecutive patients with radiosurgically treated AVMs in the brain stem for their clinical characteristics, treatment parameters, and outcomes. The main purpose of this study was to seek the specific dose and treatment volume prescription for safe and effective radiosurgery to brain stem AVMs.

\section{Patients and methods}

PATIENT POPULATION

From July 1990 to October 1997, 30 patients (18 males and 12 females) with angiographically proved brain stem AVMs underwent radiosurgical treatment at our institution. The patients' ages ranged from 7 to 66 years (mean 35.7 (SD 15.5)). The initial manifestation was haemorrhage in 24 patients, headache in three, seizure in one, obstructive hydrocephalus in one, and tinnitus in one. Before radiosurgery, 26 patients $(86.7 \%)$ had 34 haemorrhages from AVMs. The mean interval between the last haemorrhage and irradiation was 9.7 (SD 11.7) months (range 2 to 46). Three had undergone transarterial embolisation, three had other surgical interventions (ventricleperitoneal shunt placement in one, ventricular drainage in one, haematoma evacuation in one), and another three had conventional radiotherapy. At radiosurgery, 21 patients $(70 \%)$ had a fixed neurological deficit. The

Table 1 Patient characteristics $(n=30)$

\begin{tabular}{lcc}
\hline Characteristics & Incidence & $\%$ \\
\hline Sex: & 18 & 60.0 \\
Male & 12 & 40.0 \\
Female & 26 & 86.7 \\
Prior haemorrhage & 21 & 70.0 \\
Neurological signs & 14 & 46.7 \\
$\quad$ Eye movement disturbance & 7 & 23.3 \\
Cerebellar sign/ataxia & 6 & 20.0 \\
Paresis & 6 & 20.0 \\
Dysaesthesia & 3 & 10.0 \\
Lower cranial palsy/dysarthria & 3 & 10.0 \\
Vertigo/tinnitus & 3 & 10.0 \\
Facial palsy & & \\
Karnofsky score: & 10 & 33.3 \\
100 & 10 & 33.3 \\
90 & 6 & 20.0 \\
80 & 4 & 13.3 \\
$\quad \leqslant 70$ & & \\
\hline
\end{tabular}

8 September 1999

Accepted 23 September 1999 
Table 2 AVM characteristics $(n=30)$

\begin{tabular}{lcc}
\hline Characteristics & Incidence & $\%$ \\
\hline Location: & & \\
$\quad$ Midbrain (tectum) & $17(10)$ & $56.7(33.3)$ \\
Pons (peduncle) & $11(8)$ & $36.7(26.7)$ \\
$\quad$ Medulla oblongata & 2 & 6.7 \\
Diameter of the nidus $(\mathrm{cm})$ & $1.26(0.44)^{\star}$ & $0.57-2.00 \dagger$ \\
Volume of the nidus $\left(\mathrm{cm}^{3}\right)$ & $1.35(1.27)^{\star}$ & $0.10-3.92 \dagger$ \\
Volume in the brain stem & & \\
$\quad$ parenchyma $\left(\mathrm{cm}^{3}\right)$ & $0.60(0.49)^{\star}$ & $0.10-2.00 \dagger$ \\
Arterial supply: & 11 & 36.7 \\
$\quad$ BA perforator & 15 & 50.0 \\
SCA & 7 & 23.3 \\
AICA & 5 & 16.7 \\
PICA & 8 & 26.7 \\
PChA & & \\
Venous drainage: & 20 & 66.7 \\
Galenic & 11 & 36.7 \\
Petrosal & 1 & 3.3 \\
Cortical & &
\end{tabular}

* Mean (SD); † range.

most frequent symptom was the eye movement disturbances, followed by cerebellar and pyramidal signs. Most patients were ambulatory, and Karnofsky performance status score was 90 or greater in $20(66.7 \%)$ patients (mean 86.7 (SD 15.6); range 30-100). The clinical features of treated patients are summarised in table 1 .
CHARACTERISTICS OF AVMS

In all cases, the AVM characteristics were defined by cerebral angiography in combination with CT or MRI. Seventeen AVMs $(56.7 \%)$ were located in the midbrain, 11 $(36.7 \%)$ in the pons, and two $(6.7 \%)$ in the medulla oblongata. In 15 patients $(50 \%)$, the whole nidus was located within the brain stem parenchyma, and in the other 15, the nidus partially involved surrounding structures (galenic, quadrigeminal, or parapontine cisterns in 11 , thalamus in four, fourth ventricle in three, and cerebellar vermis in one). Pial or subpial lesions were excluded from the study. All irradiated lesions were small ( $\leqslant 2 \mathrm{~cm}$ in diameter). In all cases, the intra-axial component occupied less than one third of the area of brain stem parenchyma on axial section of multiplaner MRI or CT. The mean diameter of the nidus ranged from 0.57 to $2.00 \mathrm{~cm}$ (mean 1.26 $(\mathrm{SD} 0.44) \mathrm{cm}$ ), and the mean volume ranged from 0.10 to $3.92 \mathrm{~cm}^{3}$ (mean 1.35 (SD 1.27) $\mathrm{cm}^{3}$ ). The diameters of brain stem parenchymal components ranged from 0.35 to $1.62 \mathrm{~cm}$ (mean $0.89(\mathrm{SD} 0.33) \mathrm{cm}$ ), and the volumes ranged from 0.10 to $2.00 \mathrm{~cm}^{3}$ (mean 0.60 (SD 0.49) $\mathrm{cm}^{3}$ ). Most of the AVMs were supplied bilaterally by branches of the superior cerebellar artery (SCA; 15 cases), anterior inferior
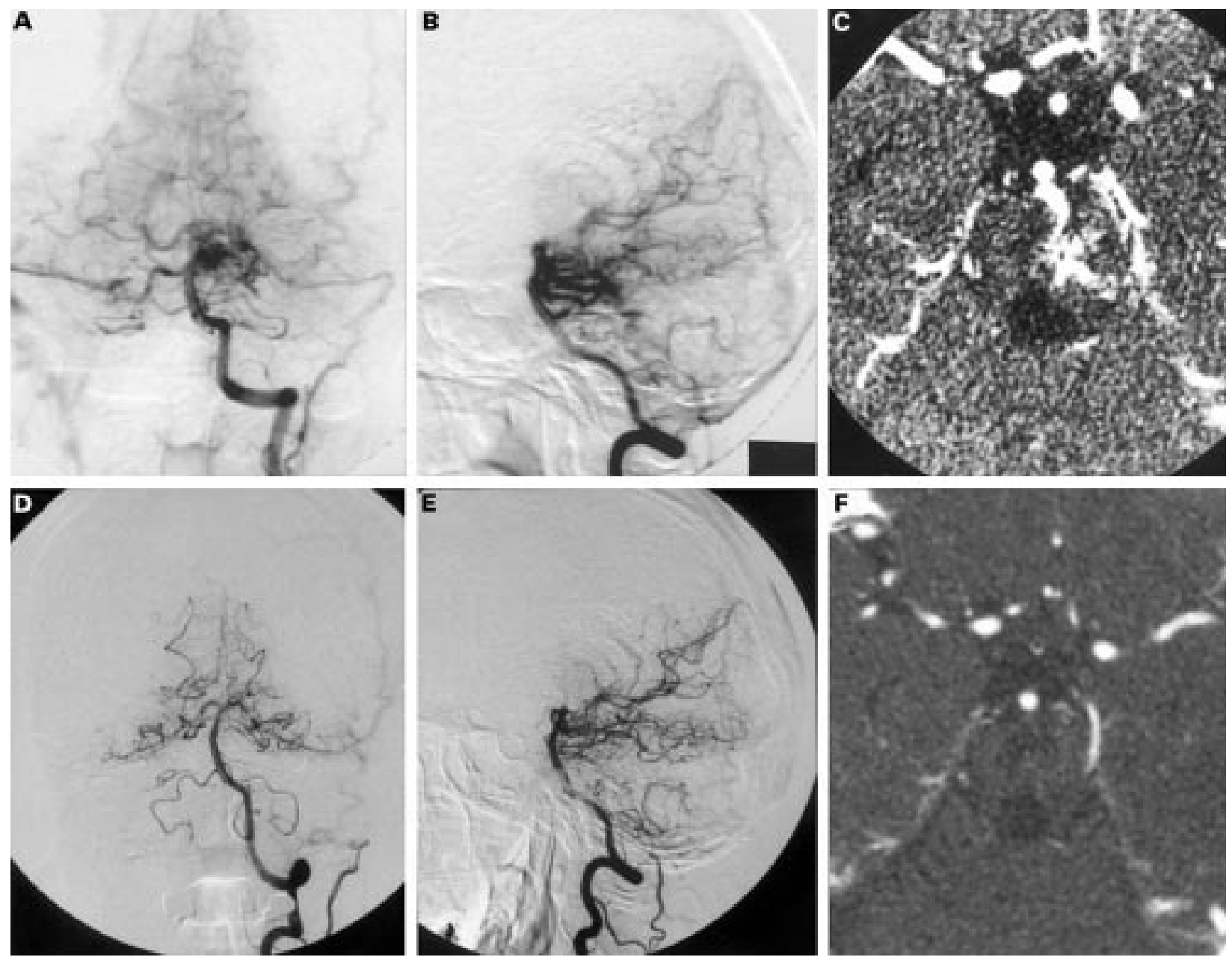

Figure 1 Neuroimages in a 39 year old woman with pontine haemorrhage. Left vertebral angiograms $(A, B)$ and contrast enhanced $C T(C)$ before radiosurgery show a ruptured pontine arteriovenous malformation (AVM). Left vertebral angiograms $(D, E)$ and contrast $C T(F)$ obtained 2 years after radiosurgery demonstratie total obliteration of the AVM. 
A

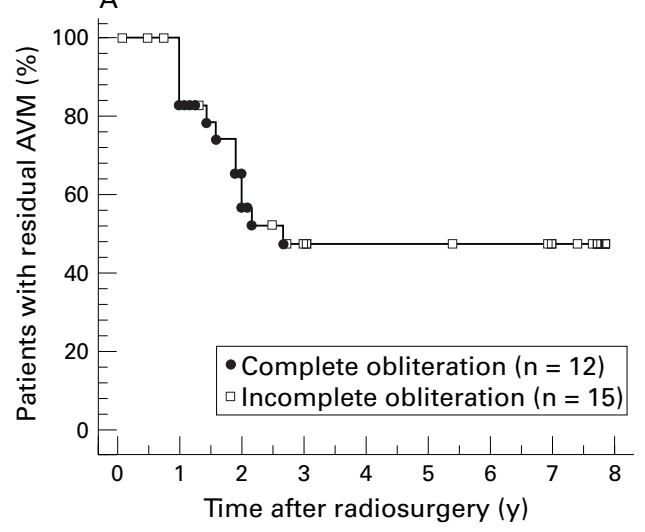

B

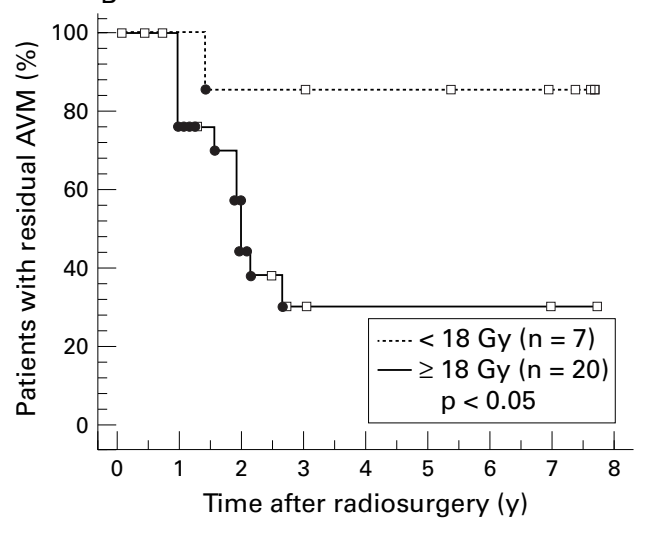

Figure 2 (A) Kaplan-Meier curve showing cumulative rate of complete obliteration for the 27 patients followed up radiologically. Patients with complete AVM obliteration are indicated with closed circles, and patients without obliteration at the last observation, which are censored at that time point, are indicated with open squares. The cumulative complete obliteration rate was $52.2 \%$ at 3 years. (B) Plots stratified by minimal target dose. The solid line denotes patients treated with standard dose ( $\geqslant 18 \mathrm{~Gy}, 20$ patients), and the dotted line denotes patients treated with a low dose $(<18 G y$, seven patients). The actuarial obliteration rates of each category were $69.4 \%$ and $14.3 \%$, respectively. The difference was significant $(p<0.05)$.

cerebellar artery (AICA; seven), posterior inferior cerebellar artery (PICA; five), lateral or medial posterior choroidal artery (PChA; eight), or the fine perforators from the basilar artery $(\mathrm{BA} ; 11)$, and 13 of these had multiple feeders. In 20 cases, the AVM drained superiorly into the galenic system via lateral mesencephalic, basal, or superior cerebellar veins. In 11 cases it drained laterally into the petrosal vein. One had partial drainage to the vein of Labbe. The summary of neuroradio- logical findings of treated AVMs are described in table 2 .

RADIOSURGICAL TREATMENT

Radiosurgery was performed using a 201 source ${ }^{60} \mathrm{Co}$ gamma unit (Elekta Instruments, Atlanta, GA, USA). Definition of the nidus and localisation of the irradiation target were done on biplane stereotactic cerebral angiography. After April 1992, stereotactic thin slice multiplaner CT or MRI was used in combination to

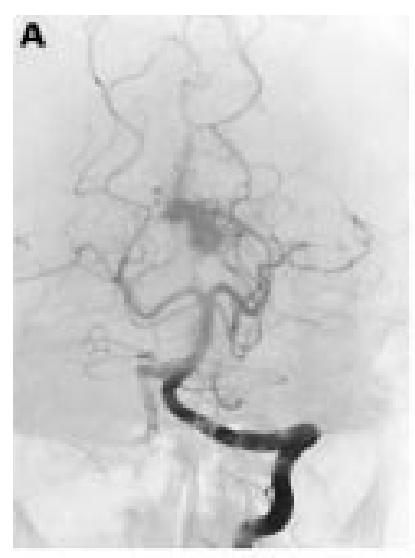

E
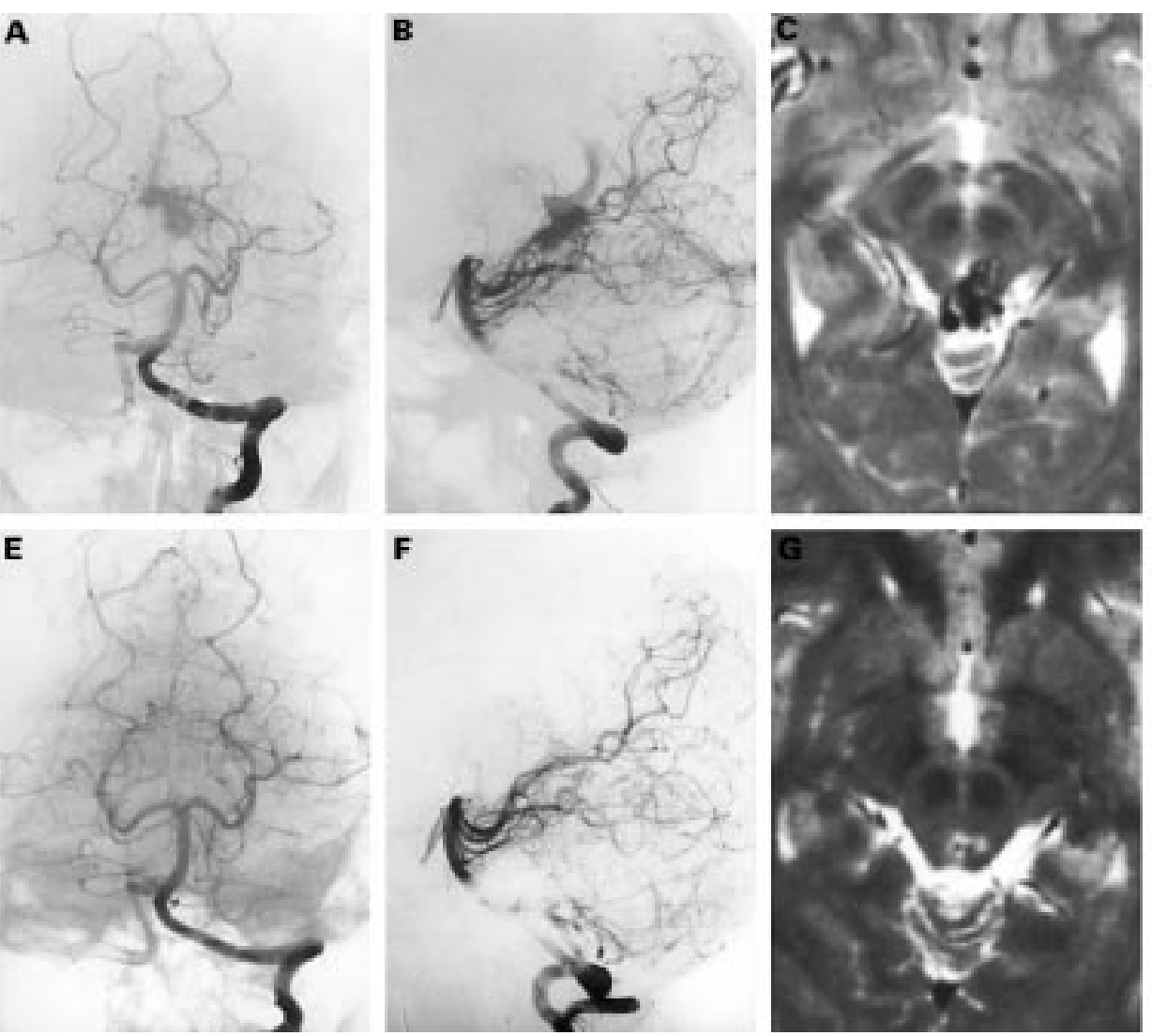

Figure 3 Neuroimages in a 16 year old girl with intraventricular haemorrhage. Left vertebral angiograms (A, B) and T2 weighted MR image (C) before radiosurgery show ruptured AVM in the tectum. T2 weighted MR image (D) obtained 6 months after radiosurgery shows asymptomatic brain stem oedema. Left vertebral angiograms $(E, F)$ and $T 2$ weighted $M R$ image $(G)$ obtained a year after radiosurgery show total obliteration of the AVM and a reversal of the oedema. 

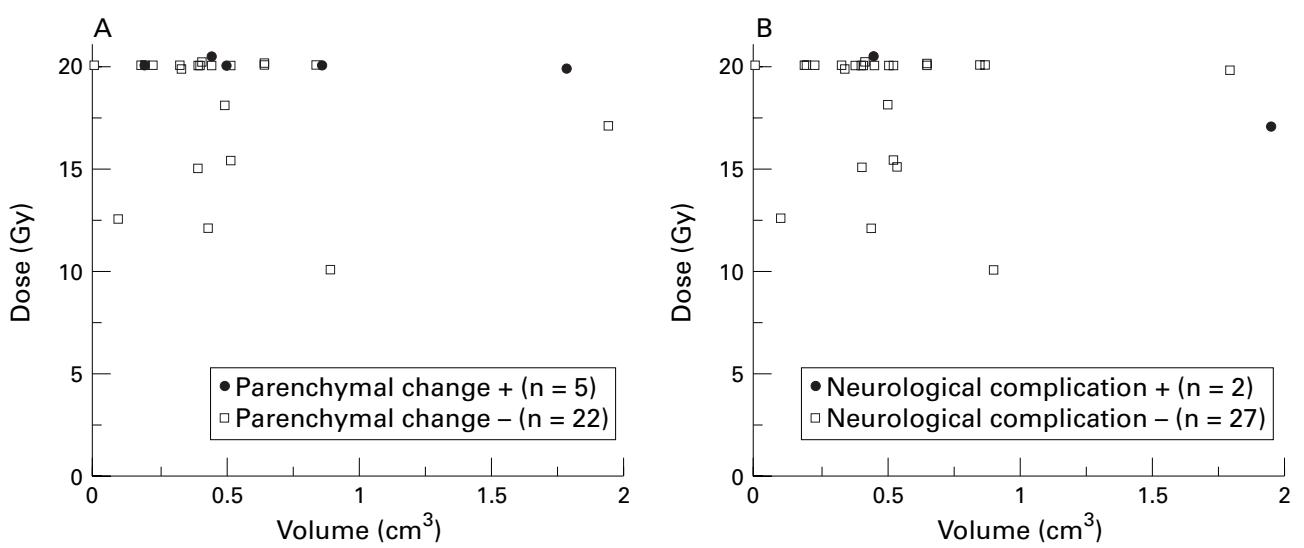

Figure 4 Scatter plot of nidus volume $v$ minimum target dose. (A) Patients developing surrounding parenchymal change are indicated with closed circles and patients without parenchymal imaging change are indicated with open squares. (B) Patients developing symptomatic radiation injury are indicated with closed circles and patients without neurological deterioration are indicated with open squares.

obtain precise three dimensional configurations of the nidus. A MicroVAX computer system (Digital Equipment Corporation, Westminster, MA, USA) was used in complex dose planning. All patients had irradiation of the entire nidus in a single session encompassed by $30-80 \%$ (mean 53.0 (SD 8.9) isodose contour. The mean radiation dose to the AVM margin (minimum target dose) was 18.4 (SD 2.9) Gy (range 10-20.4). Initially, the lower doses of 10-17 Gy were used in seven patients, but the lack of adverse effect of the irradiation at the higher end of this range prompted us to scale up the doses in a stepwise fashion to the standard radiosurgical dose of 18-20.4 Gy. The mean dose to the centre of the AVM (maximum target dose) was 35.5 (SD 6.7) Gy (range 20-50 Gy). The number of isocentres used varied from one to 10 (mean 3.4 (SD 2.4) per patient). All patients were discharged from the hospital uneventfully on the next day.

STATISTICAL ANALYSIS

Cumulative rates of angiographical obliteration and post-treatment survival rate were calculated using the actuarial method of KaplanMeier, and log rank (Mantel-Cox) and PetoPeto-Wilcoxon test were used for statistical analyses. For non-parametric variables, the Mann-Whitney rank test was used. The level of statistical significance was $\mathrm{p}<0.05$.

Table 3 Treatment outcomes

\begin{tabular}{llr}
\hline Outcomes & Incidence & $\%$ \\
\hline Clinical outcome: & $12 / 29$ & 41.3 \\
$\quad$ Improved & $12 / 29$ & 41.3 \\
Stable & $0 / 29$ & 0.0 \\
Deteriorated & $5 \star / 29$ & 17.2 \\
$\quad$ Dead & $12 / 27$ & 44.4 \\
Angiographical outcome: & $3 / 27$ & 11.1 \\
$\quad$ Total obliteration & $12 / 27$ & 44.4 \\
$\quad$ Subtotal obliteration & & \\
$\quad$ Partial obliteration & $5 / 27$ & 18.5 \\
Adverse effects: & $2 / 29$ & 6.9 \\
$\quad$ Brain stem oedema & $0 / 29$ & 0.0 \\
$\quad$ Symptomatic radiation injury, transient & & \\
Symptomatic radiation injury, permanent & & \\
Post-treatment haemorrhage: & $4 / 29$ & 13.8 \\
$\quad$ Fatal & $1 / 29$ & 3.5 \\
$\quad$ Non-fatal & & \\
\hline
\end{tabular}

*One patient died from unrelated cause.

\section{Results}

CLINICAL OUTCOME

The follow up data were available in 29 of 30 patients $(96.7 \%)$ with only one patient lost to follow up. At the last follow up 6 to 96 months (mean 52.2 (SD 31.3)) after the treatment, nine remained and an additional eight improved to be symptom free. Four improved significantly but still had a focal neurological deficit. Three had fixed neurological deficit that had existed before radiosurgery. Five patients died; four from intracranial haemorrhage, and one from pneumonia. The 5 year survival rate after radiosurgery calculated by the KaplanMeier method was $87.5 \%$. The mean Karnofsky performance status score at the last follow up in patients without post-treatment haemorrhage was significantly higher than that at the time of radiosurgery (93.3 (SD 15.5) $v 86.7$ (SD 15.6); $\mathrm{p}<0.05)$.

\section{OBLITERATION RESULTS}

Twenty seven patients underwent neuroradiological evaluation 6-96 months after radiosurgery. One patient refused any neuroradiological examination, one died shortly after radiosurgery without neuroradiological check up, and one was lost to follow up. At the last angiographical evaluation, complete obliteration was confirmed in $12(44.4 \%)$ (fig 1 ), subtotal obliteration (no visualisation of nidus with persistent AV shunt) in three $(11.1 \%)$, and partial obliteration in 12 $(44.4 \%)$. The actuarial complete obliteration rate of all treated AVMs was $52.2 \%$ at 3 years (fig $2 \mathrm{~A}$ ). When assessed separately, lesions receiving standard radiosurgical dose (18-20Gy at periphery) obliterated significantly better than lesions receiving low dose treatment $(<18 \mathrm{~Gy})$, with the actuarial 3 year rates of $69.4 \%$ versus $14.3 \%$ ( $p<0.05$; fig 2 B). No other clinical characteristics or treatment parameters influenced the obliteration rate.

COMPLICATIONS

Two patients $(6.9 \%)$ with mid-brain AVM experienced symptomatic radiation injury seven and 24 months after irradiation; ptosis and ataxia in one, eye movement disorder in the other. Both patients were given oral 
corticosteroid, and the symptom resolved within a year. No patient had permanent deficit attributable to radiosurgery. Among 27 patients who underwent follow up neuroradiological examinations, radiation induced brain stem oedema was detected in five cases $(18.5 \%)$ at $5-30$ months after irradiation (fig 3). All these findings were reversible, and were asymptomatic in four, and transiently symptomatic in one. Another patient developed transient eye movement disorder without neuroradiologically detectable parenchymal change. Prescribed radiation dose to the AVM margin and volume of the AVM are shown in fig 4 . There were no significant correlations between clinical/radiological adverse effects and lesion size/dose.

HAEMORRHAGE AFTER TREATMENT

During the 126.5 person-years of follow up, five of 29 patients $(17.2 \%)$ had intracranial haemorrhage from irradiated AVMs (fig 5), yielding a post-treatment annual bleeding rate of $4.0 \% \quad(95 \%$ confidence interval; $0.6 \%$ -
$7.4 \%$ ). The intervals between the radiosurgery and the haemorrhagic event were 1-92 months (mean 29.4 (SD 40.0 months). Two haemorrhages were seen in the 1st year, one each in the 2nd, 4th, and 8th year after the treatment, resulting in annual bleeding rates of $5.9 \%$ for the first 2 years and $2.7 \%$ for 3 to 8 years. Among the patients with longer than 3 year follow up, those who received a standard dose had an annual bleeding risk of $1.9 \%$, and those who received a low dose carried a higher rate of $3.2 \%$. Of the five patients who had a haemorrhage, four had had a previous haemorrhage. The outcomes were grave: four patients died of the haemorrhage and one remained unchanged. The actuarial haemorrhage free survival rate was $93.1 \%$ in 1 year, $88.9 \%$ in 2 years, and $80.8 \%$ in 7 years (fig 6 ). The rate did not correlate with pretreatment haemorrhage, or any clinical characteristics. No patient experienced haemorrhage after total obliteration, with a mean follow up of 33.0 (SD 29.2) months. The overall treatment outcome is summarised in table 3.
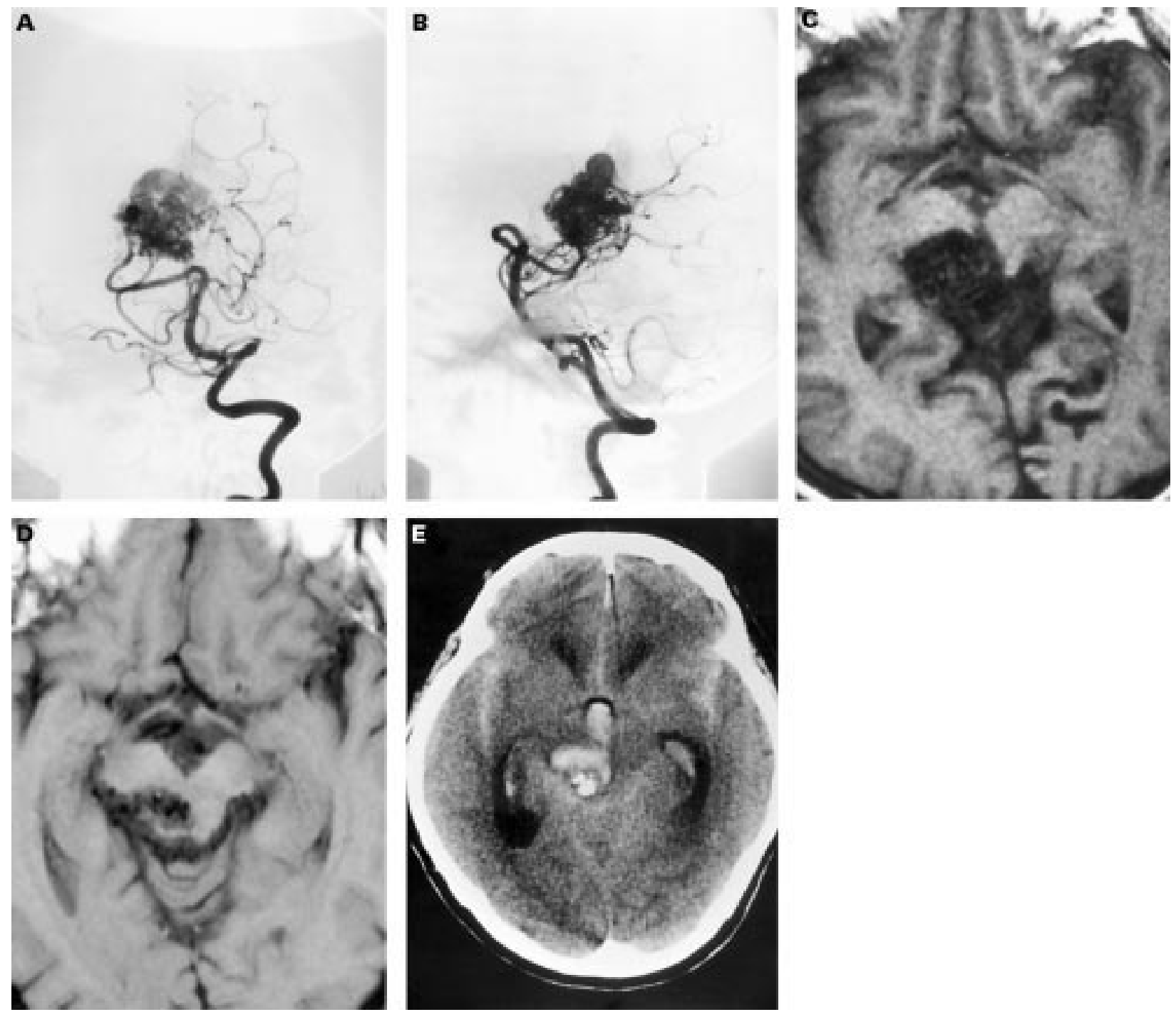

Figure 5 Neuroimages in a 56 year old man with headache. Left vertebral angiograms $(A, B)$ and T1 weighted MR image $(C)$ before radiosurgery show an AVM in the midbrain. T1 weighted MR image obtained 5 years after radiosurgery (D) shows the residual AVM nidus. CT obtained 8 years after radiosurgery (E) shows fatal bleeding from the AVM. 


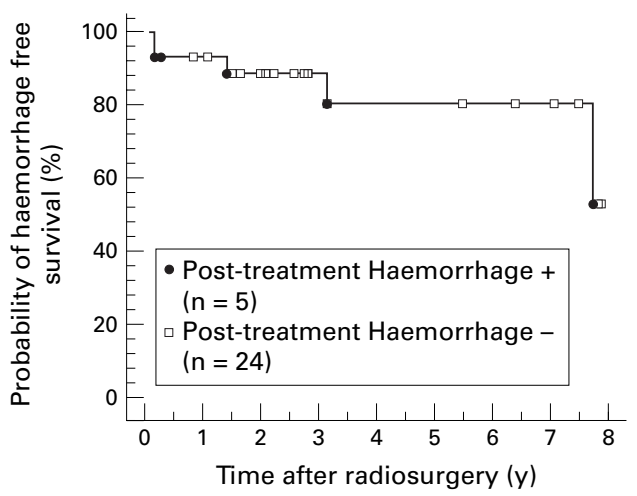

Figure 6 Probability of haemorrhage free survival after radiosurgery.

\section{Discussion}

BRAIN STEM AVMS

Arteriovenous malformations of the brain stem represent only $2 \%-6 \%$ of all cerebral AVMs,${ }^{6}{ }^{15-19}$ but they pose a great management challenge. Several studies have indicated that these AVMs in fact have a high risk of bleeding. About $80 \%-90 \%$ of patients initially presented with an intracranial haemorrhage, ${ }^{6} 161920$ and the risk of haemorrhage in untreated patients was estimated to be $60 \%$ in 10 years. ${ }^{20}$ Unfortunately, there is no solid consensus on the optimal treatment protocols for these lesions at present. $^{21}$

Many authors reported favourable results with direct surgical excision utilising modern microsurgical techniques, but most of these reports are based on small series involving highly selected cases $^{46111516}$ or a single case report. ${ }^{22}{ }^{23}$ Drake et $a l^{16}$ reported the surgical results of 15 brain stem AVMs: successful extirpation was achieved in two pial lesions, and four died after surgery. Batjer and Samson ${ }^{15}$ successfully resected four brain stem AVMs, but one patient died. In the series of Solomon and Stein, ${ }^{6}$ nine of 12 patients were surgically treated and complete removal was achieved in eight, but the morbidity rate reached $22 \%$. In the recent report of Lowton et $a l{ }^{4}$ eight AVMs involving the brain stem were surgically extirpated without significant morbidity. Sisti et $a l^{4}$ reported successful total resection in eight of 11 brain stem AVMs, but the rate remained $50 \%$ (3/6) among the cases limited to the intraparenchymal lesions, and two such patients died. Yasargil ${ }^{19}$ stated in 1993 that parenchymal brain stem AVMs remain beyond the limits of the microsurgical technique. These reports indicate that although pial or subpial lesions can be safely extirpated by surgery, attempts to resect lesions with a parenchymal component lead to high rates of surgical morbidity and a low rate of complete removal. This would not be surprising as the dissection within the brain stem is potentially very hazardous ${ }^{16}$ and the arterial feeder of the AVMs often also supplies surrounding vital parenchyma as well. ${ }^{6}$ For similar reasons, state of the art endovascu- lar techniques have not exerted major therapeutic influence either, ${ }^{46}$ with few exceptions. $^{25}$

RADIOSURGERY OF BRAIN STEM AVMS

Currently, stereotactic radiosurgery seems to be the treatment of choice for brain stem AVMs located within the parenchyma. In fact, several gamma knife users have shown that a proportion of patients with "inoperable" brain stem AVM were successfully treated with radiosurgery. ${ }^{128-10}$ However, the safety and efficacy of radiosurgery for such AVMs would need further verification. Steiner et $a l^{8}$ briefly mentioned their experience of 57 brain stem AVMs and stated that complete obliteration was confirmed in 20 of 28 patients $(71.4 \%)$ after a 2 year follow up. However, they did not give clinical characteristics and treatment parameters, or investigate adverse effects caused by the treatment. Duma et $a l^{10}$ reported their preliminary results of radiosurgery for 28 cases of brain stem AVMs. In their series, the mean volume of the nidus and minimal target dose delivered were $5.4 \mathrm{~cm}^{3}$ and $20.6 \mathrm{~Gy}$. Complete obliteration was attained in seven of eight patients $(87.5 \%)$ on follow up angiography performed 2 years later. Four patients $(14.3 \%)$ developed symptomatic radiation injury, of which two $(7.1 \%)$ had permanent deficit and one $(3.6 \%)$ died. The dose-volume prescription used in the affected patients was "standard". Flickinger et $a l^{26}$ reported that brain stem oedema was "symptomatic" in seven of eight cases (87.5\%), and Kondziolka et $a l^{9}$ stated that they would be hesitant to perform radiosurgery for brain stem AVMs larger than $2.5 \mathrm{~cm}$ in diameter. Similar cautions for brain stem radiosurgery have also been given for linac based radiosurgery ${ }^{13}{ }^{14}$ : in the series of Alexander et $a l^{13}$ symptomatic radiation injury was seen in five of six $(83.3 \%)$ patients with brain stem AVMs; three of which were considered major. These reports suggests that brain stem AVMs have a higher risk of radiation injury than those in other locations, potentially resulting in serious neurological deterioration. Although several risk prediction models are currently available as a guideline for dose selection for AVM radiosurgery, ${ }^{27}{ }^{28}$ precise dose-volume limits for brain stem AVMs have not been established. ${ }^{10}$

\section{ANALYSIS OF PRESENT SERIES}

Because the optimal dose is determined on the balance between expected obliteration rates and corresponding risks of radiation injury, knowledge on tolerable doses is essential in planning radiosurgical treatment, especially for lesions located in the eloquent area of the brain. We have shown here that carefully selected patients with small deep parenchymal brain stem AVMs with a parenchymal component less than $2 \mathrm{~cm}^{3}$ in volume could undergo safe and effective radiosurgery using a standard radiosurgical dose (18-20 Gy). 
The overall AVM obliteration rate in our series $(52.2 \%$ at 3 years) was lower than previously published numbers on larger radiosurgical series. ${ }^{1-3}{ }^{29-31}$ The most likely reason is that lower doses delivered to the patients during the earlier period were insufficient. In fact, the only factor which affected the rate of obliteration was the minimum target dose, although the analysis of volume effect in our series is limited by the small treated volumes in most cases. This is in agreement with several other studies also showing that the minimum target dose is the most significant factor for the obliteration rate of AVMs. ${ }^{27}{ }^{32}{ }^{33}$ The risk for radiation injury, on the other hand, correlated both with doses and with irradiated volumes. ${ }^{27} 28$ 34-37 Therefore, it is possible that the standard dose of 18-20 Gy could cause unacceptable complications if the volumes of AVMs are ignored, because radiation dose outside the prescribed target volume becomes significant in proportion to the treated volume. This could induce unacceptable symptomatic injury especially in central locations. ${ }^{12} 38$

In our series, five patients $(17.2 \%)$ had posttreatment haemorrhages from irradiated but not yet obliterated AVM, four of whom died. This finding confirmed the general consensus that radiosurgery does not reduce the rate of bleeding when the AVMs remain partially obliterated. ${ }^{1239-41}$ In addition, the significantly higher mortality rate after haemorrhage than found in previous reports probably reflected the critical location of the brain stem AVMs. ${ }^{1} 293139-41$ With such a relatively high bleeding rate and mortality, our current series may still be short of demonstrating a clear benefit of radiosurgery on survival or functional survival. However, the significant rate of complete obliteration of the AVM after standard dose radiosurgery, in combination with the fact that no bleeding was seen from completely obliterated AVMs, should justify the radiosurgical treatment of brain stem AVMs. Although further studies with larger series and longer follow up are needed to confirm this more clearly, our present study adds a valuable contribution to the knowledge on the dose and treatment volume prescription for brain stem AVMs.

In summary, our results presented here are in favour of the notion that radiosurgery should be the treatment of choice for patients with intraparenchymal brain stem AVMs, in which standard radiosurgical doses can be delivered if the intraparenchymal nidus volume is sufficiently small. However, post-treatment haemorrhage remains a significant problem of this technique as this is associated with a high mortality rate.

We are grateful to Dr Hiroshi Abe, Department of Neurosurgery, Brain Research Institute, Niigata University, and Dr tan Bokuto Hospital, for providing the radiographic data. This tan Bokuto Hospital, for providing the radiographic data. This
work was supported in part by a Grant-in-Aid for Scientific work was supported in part by a Grant-in-Aid for Scientific Research from the Ministry of Education, Science, and Culture of Japan.

1 Steiner L, Lindquist C, Adler JR, et al. Clinical outcome of radiosurgery for cerebral arteriovenous malformations. $\mathcal{F}$ Neurosurg 1992;77:1-8.
2 Lunsford LD, Kondziolka D, Flickinger JC, et al. Stereotactic radiosurgery for arteriovenous malformations of the tic radiosurgery for arteriovenous
brain. $\mathcal{F}$ Neurosurg 1991;75:512-24.

3 Yamamoto Y, Coffey RJ, Nichols DA, et al. Interim report on the radiosurgical treatment of cerebral arteriovenous malformations. The influence of size, dose, time, and technica factors on obliteration rate. $\mathcal{F}$ Neurosurg 1995;83:832-7.

4 Lawton MT, Hamilton MG, Spetzler RF. Multimodality reatment of deep arteriovenous malformations: thalamus, basal ganglia, and brain stem. Neurosurgery 1995;37:29-35.

5 Sasaki T, Kurita H, Saito I, et al. Arteriovenous malformations in the basal ganglia and thalamus: management and results in 101 cases. $\mathcal{F}$ Neurosurg $1998 ; 88: 285-92$.

6 Solomon RA, Stein BM. Management of arteriovenous malformations of the brain stem. F Neurosurg 1986;64:857-64.

7 Yamamoto M, Jimbo M, Lindquist C. Radiation-induced edema after radiosurgery for pontine arteriovenous malformation. A case report and detection by magnetic resonance mation. A case report and detection by

8 Steiner L, Lindquist C, Cail W, et al. Microsurgery and Steiner $\mathrm{L}$, Lindquist $\mathrm{C}$, Cail W, et al. Microsurgery and
radiosurgery in brain arteriovenous malformations. $\mathscr{f} \mathrm{Neu}$ rosurg 1993;79:647-52.

9 Kondziolka D, Lunsford LD, Flickinger JC. Intraparenchymal brain stem radiosurgery. Neurosurg Clin N Am 1993;4: 469-79.

10 Duma CM, Lunsford LD, Kondziolka D, et al. Radiosurgery for vascular malformations of the brain stem. Acta Neurochir (Suppl) 1993;58:92-7.

11 Chyatte D. Vascular malformations of the brain stem. $\mathcal{F}$ Neurosurg 1989;70:847-52.

12 Flickinger JC, Kondziolka D, Maitz AH, et al. Analysis of neurological sequelae from radiosurgery of arteriovenous malformations: how location affects outcome. Int $\mathcal{f}$ Radiat malformations: how location affect

13 Alexander III E, Loeffler JS. Radiosurgery for intracranial vascular malformations: techniques, results, and complications. Clin Neurosurg 1992;31:273-91.

14 Engenhart R, Wowra B, Debus J, et al. The role of high-dose, single-fraction irradiation in small and large intracranial arteriovenous malformations. Int $f$ Radiat Oncol Biol Phys 1994;30: 521-9.

15 Batjer H, Samson D. Arteriovenous malformations of the posterior fossa: clinical presentation, diagnostic evaluation, and surgical treatment. $\mathcal{F}$ Neurosurg 1986;64:849-56.

16 Drake CG, Friedman AH, Peerless SJ. Posterior fossa arteriovenous malformations. $\mathcal{F}$ Neurosurg 1986;64:1-10.

17 Matsumura H, Makita Y, Someda K, et al. Arteriovenous malformations in the posterior fossa. F Neurosurg 1977;47: 50-6.

18 Perret G, Nishioka H. Report on the cooperative study of intracranial aneurysms and subarachnoid hemorrhage. 545 cases of cranio-cerebral arteriovenous malformations and fistulae reported to the cooperative study. $₹$ Neurosurg 1966;25:467-90.

19 Yasargil MG. Infratentrial (central) AVMs. In: Yasargil MG, eds. Microneurosurgery. Vol IIIB. Stuttgart: Georg Thieme Verlag, 1993:358-61.

20 Ochiai C. Natural history of brain stem vascular malformations: clinical features, bleeding properties and surgical indications. Neurosurgeons 1991;10:207-29. (In Japanese.)

21 Ausman JI, Samson D, Steiner L, et al. What is your general approach to the management of brain stem AVMs? Surg Neurol 1995;44:107-8.

22 Sugiura K, Baba M. Total removal of an arteriovenous malformation embedded in the brain stem. Surg Neurol 1990;34:327-30.

23 Yonekawa Y, Handa $\mathrm{H}$, Taki W. Total removal of a brain stem arteriovenous malformation: case report. Neurosurgery 1983;13:443-6.

24 Sisti MB, Kader A, Stein BM. Microsurgery for 67 intracranial arteriovenous malformations less than $3 \mathrm{~cm}$ in diameter. $\mathcal{F}$ Neurosurg 1993;79:653-60.

25 Nakahara I, Handa H, Nishikawa $M$, et al. (A midbrain arteriovenous malformation at quadrigeminal plate completely obliterated by embolization.) No Shinkei Geka 1993;21:67-72. (In Japanese.)

26 Flickinger JC, Lunsford LD, Kondziolka D, et al. Radiosurgery and brain tolerance: an analysis of neurodiagnostic imaging changes after gamma knife radiosurgery for arteriovenous malformations. Int $\mathcal{f}$ Radiat Oncol Biol Phys 1992;23:19-26.

27 Flickinger JC. The integrated logistic formula and prediction of complications from radiosurgery. Int $\mathcal{F}$ Radiat Oncol Bion of complications from $1989 ; \mathbf{1 7}: 879-85$.

28 Lax I, Karlsson B. Prediction of complications in $\gamma$ knife radiosurgery of arteriovenous malformation. Acta Oncol 1996;35:49-55.

29 Betti OO, Munari C, Rosler R. Stereotactic radiosurgery with the linear accelerator: treatment of arteriovenous malformations. Neurosurgery 1989;24:311-21.

30 Colombo F, Pozza F, Chierego G, et al. Linear accelerator radiosurgery of cerebral arteriovenous malformations: an update. Neurosurgery 1994;34:14-20.

31 Friedman WA, Bova FJ. Linear accelerator radiosurgery for arteriovenous malformations. F Neurosurg 1992;77:832-41.

32 Flickinger JC, Pollock BE, Kondziolka D, et al. A dose-response analysis of arteriovenous malformation obliteration after radiosurgery. Int $\mathcal{F}$ Radiat Oncol Biol Phys 1996;36:873-9.

33 Karlsson B, Lindquist C, Steiner L. Prediction of obliteration after gamma knife surgery for cerebral arteriovenous malformations. Neurosurgery 1997;40:425-30. 
34 Steinberg GK, Fabrikant JI, Marks MP, et al. Stereotactic heavy-charged-particle Bragg-peak radiation for intracraovenous malformations. $N$ Engl f Med 1990;323 96-101.

35 Kurita H, Kawamoto S, Sasaki T, et al. (Indications and results of gamma knife radiosurgery for cerebral arteriovenous malformations.) fpn f Neurosurg 1998;7:95-101. (In Japanese.)

36 Voges J, Treuer H, Sturm V, et al. Risk analysis of linear accelerator radiosurgery. Int $\mathcal{F}$ Radiat Oncol Biol Phys 1996;36:1055-63.

37 Flickinger JC, Kondziolka D, Pollock BE, et al. Complications from arteriovenous malformation radiosurgery: multivariate analysis and risk modeling. Int $\mathcal{F}$ Radiat Oncol Biol Phys 1997;38:485-90.
38 Karlsson B, Lax I, Söderman M. Factors influencing the risk for complications following $\gamma$ knife radiosurgery of cerebral arteriovenous malformations. Radiot Oncol 1997;43:27580

39 Friedman WA, Blatt DL, Bova FJ, et al. The risk of hemorrhage after radiosurgery for arteriovenous malformations. $\mathcal{f}$ Neurosurg 1996;84:912-9.

40 Pollock BE, Flickinger JC, Lunsford LD, et al. Hemorrhage risk after stereotactic radiosurgery of cerebral arteriovenous malformations. Neurosurgery 1996;38:652-9.

41 Karlsson B, Lindquist C, Steiner L. Effect of $\gamma$ knife surgery on the risk of rupture prior to AVM obliteration. Minim Invas Neurosurg 1996;39:21-7.

\section{HISTORICAL NOTE}

\section{Wallenberg's syndrome}

In his time, Adolf Wallenberg (1862-1949) was renowned for his careful history taking and neurological examination, and for his insistence on clinicopathological confirmation. With Edinger and Gordon Holmes, he described the avian brain. He was responsible for relating the olfactory system to recognition and taste for food; he documented the anatomy of the trigeminal lemniscus in 1900 and provided a clinical masterpiece in his depiction of lateral medullary infarction, remembered as Wallenberg's syndrome. ${ }^{1}$

The earliest known description of lateral medullary infarction was given in 1810 not by Wallenberg, but by Gaspard Vieusseux of Geneva, ${ }^{2}$ at the Medical and Chirurgical Society of London:

"Vertigo, unilateral facial numbness, loss of pain and temperature appreciation in the opposite limbs, dysphasia[sic] and hoarseness, minor tongue involvement, hiccups (cured by taking up the habit of a morning cigarette) and a drooped eyelid."

However, Wallenberg's case report ${ }^{3}$ in 1895 amplified the clinical signs with accurate localisation of the lesion, which he later proved at postmortem.

Wallenberg published four papers on the syndrome. The 1895 paper provided the clinical findings in his first patient. Based on the anatomical work of Duret, Wallenberg thought that the lesion was in the lateral medulla supplied by the posterior inferior cerebellar artery (PICA). The second paper (1901) described the postmortem medullary infarction and a stenosis at the origin of the PICA with total occlusion $2 \mathrm{~cm}$ distally. ${ }^{4}$ The third paper reported another single case ${ }^{5}$ and by 1922 , he had reported his 15 th patient with clinicopathological correlations. The first patient was:

"A 38-year-old man, with poor vision caused by a pre-existing ocular condition (cataract on the left side, corneal scarring and anterior synechia on the right side) suffered an attack of vertigo without loss of consciousness. At the same time he developed pain and hyperaesthesia on the left side of the face and body, hypoaesthesiae of the right half of the face, and loss of pain and temperature sensitivity in the right extremities and the right half of the torso, with retention of the sense of touch. There was paralysis of swallowing; impaired sensation on the mucosa of the mouth, throat and palate; disturbed motility of the soft palate (on the first day bilateral, later left-sided); total paralysis of the left recurrent laryngeal nerve, and paresis of the left hypoglossal muscle, with no disturbance in the innervation of the facial muscles. $\mathrm{He}$ also had ataxia of the left extremities without impairment of gross strength, and he fell to the left side. The pulse became slower...During the ensuing days the sensitivity of the right half of the face returned to normal. The hyperaesthesia of the left half of the body disappeared, and that of the left trigeminal region changed to anaesthesia predominantly for pain and temperature (less for proprioceptive and electrocutaneous sensations), with suppression of the corneal and conjunctival reflexes. The pulse quickened again, but the other disturbances remained. On the eighth day an herpetic eruption appeared on some of the analgesic areas: the left face (including nasal mucosa; the sensitivity of the mouth and throat had returned), right shoulder, and right inguinal region."

There followed a detailed account of persisting clinical features 2 to 3 months after the attack:

"In the following weeks, the difficulty swallowing, the falling to the left, and the ataxia gradually disappeared. The other phenomena. . remained unchanged." A Horner's syndrome was probably missed because the patient had a cataract in one eye and corneal scar in the other.

The arterial lesions of the LMS are principally atherothrombotic vertebral and basilar arteries supplying the PICA, with smaller numbers of dissections, and embolism.? Sacco et al collected data from all the large reported series. MRI abnormalities ${ }^{89}$ are evident in more than $90 \%$ of patients and vary in size. The prognosis for the majority is good, with a large measure of functional independence.

Wallenberg painted a distinctive picture, which has not been bettered after 100 years. Max Nonne wrote about him: "As a human being, Wallenberg was characterised by a rare modesty and he was unusually warm-hearted and helpful"'

Victor Von Weizsäcker noted:

". . .such mastery is only conferred on him who works with endless patience and renouncement, with a proud conscience..."

Wallenberg, ${ }^{10}$ the son of the physician Samuel Wallenberg, was born on 10 November 1862 in Stargard (near Danzig, then in WesternPrussia). His grandfather was a Rabbi. Samuel died when Adolf was six. As a boy, Adolph learned to play the violin. With his brother Georg a cellist, who became a math- ematician, and Theodor a pianist, who became an ophthalmologist, he formed a trio. Wallenberg studied medicine, under Erb in Heidelberg, and in Leipzig, under Strümpell and Weigert. He wrote a thesis on poliomyelitis. He returned to Danzig, as a physician at the city hospital. When the horse from his carriage bolted, in 1891, he suffered from a skull base fracture causing diplopia and anosmia; he later believed it caused his personality to become more compulsive. He refused offers of several chairs, preferring to stay in his homeland. In 1907, he was appointed chief physician to the city hospital. During the first world war, he was advisor to the 17 th army. He received the Erb medal in 1929, for his "merits in the field of anatomy, physiology, and pathology of the nervous system". A prolific researcher and writer, he published 47 papers before retiring. In 1938 , he had to end his career, under intolerable pressure from the Nazis. Only at the relentless insistence of his wife did they flee through Holland to Oxford, where he worked with LeGros Clark. In 1943, he emigrated to the USA, 50 miles from Chicago.

Wallenberg died from ischaemic heart disease in 1949.

J M S PEARCE

304 Beverley Road, Anlaby, Hull HU10 7BG, E Yorks, UK

1 Barnett HJM, Meldrum H. Wallenberg's syndrome. In: Koehler PJ, Bruyn GW, Pearce JMS, eds. Common eponyms in neurological practice. Oxford: Open University Press, 2000 (in press)

2 Marcet A. History of a singular nervous or paraytic affection attended with anomalous morbid sensations. Medico-Chirurgical Transactions $1811 ; 2: 215-33$

3 Wallenberg A. Akute Bulbäraffektion (Embolie der Arteria cerebelli post inf sinistra). Archives fur Psychiatry 1895;27:504-40.

4 Wallenberg A. Anatomischer Befund in einen als acute Bulbäraffection (Embolie der Art. cerebellar post. sinistr) beschriebenen Falle. Arch Psych Nervenkrankh 1901;34:923-59.

5 Wallenberg A. Verschluss der arteria cerebelli Wallenberg A. Verschluss der arteria cerebelli
inferior posterior sinistra. Neurologische Zentralinferior posterior sinist $1915 ; 34: 236-47$.

6 Wallenberg A. Verschluss der arteria cerebelli inferior posterior dextra (mit sektionbefund). Deutsche Zeitschrift fur Nervenheilk 1922;73: 189-212

Wilkins RH, Brody IA. Wallenberg's syndrome. Arch Neurol 1970;22:379-82

8 Sacco RL, Freddo L, Bello JA, et al. Wallenberg's lateral medullary syndrome: clinicalging correlations. Arch Neurol 1993;50:609-614.

9 Kim JS, Lee JH, Choi CG. Patterns of lateral medullary infarction: vascular lesion-magnetic resonance imaging correlation of 34 cases. Stroke 1998;29:645-52.

10 Wallenberg-Chermak $M$. Adolf Wallenberg (1862-1939). In: Kolle K. Grosse Nervenärzte. Vol. 3. Stuttgart: Thieme Verlag, 1963:190-6. 